\title{
Nadgradnja algoritma FLORS za besednovrstno označevanje slovenskih besedil
}

\author{
Domen Kavran \\ Univerza v Mariboru, Fakulteta \\ za elektrotehniko, \\ računalništvo in informatiko \\ Koroška cesta 46, \\ 2000 Maribor, Slovenija \\ domen.kavran@student.um.si \\ Rok Potočnik \\ Univerza v Mariboru, Fakulteta \\ za elektrotehniko, \\ računalništvo in informatiko \\ Koroška cesta 46 , \\ 2000 Maribor, Slovenija \\ rok.potocnik4@student.um.si
}

\author{
Robi Novak \\ Univerza v Mariboru, Fakulteta \\ za elektrotehniko, \\ računalništvo in informatiko \\ Koroška cesta 46 , \\ 2000 Maribor, Slovenija \\ robi.novak1@student.um.si \\ Luka Pečnik \\ Univerza v Mariboru, Fakulteta \\ za elektrotehniko, \\ računalništvo in informatiko \\ Koroška cesta 46, \\ 2000 Maribor, Slovenija \\ luka.pecnik@student.um.si
}

\author{
Jan Banko \\ Univerza v Mariboru, Fakulteta \\ za elektrotehniko, \\ računalništvo in informatiko \\ Koroška cesta 46, \\ 2000 Maribor, Slovenija \\ jan.banko@student.um.si \\ Borko Bošković \\ Univerza v Mariboru, Fakulteta \\ za elektrotehniko, \\ računalništvo in informatiko \\ Koroška cesta 46, \\ 2000 Maribor, Slovenija \\ borko.boskovic@um.si
}

\section{POVZETEK}

Besednovrstno označevanje je postopek razpoznavanja besednih vrst $\mathrm{v}$ besedilu. Algoritem FLORS učinkovito izvaja besednovrstno označevanje z lokalnim kontekstom posamezne besede. V članku smo algoritem FLORS nadgradili za besednovrstno označevanje slovenskega jezika. Izboljšavo smo dosegli z odstranitvijo morfoloških značilk, vezanih na angleški jezik. Uporabili smo tudi analizo poglavitnih komponent. Z opisano spremembo nabora značilk smo dosegli uspešnost 85,16 \%. Ugotavljamo, da se algoritem lahko uporabi za označevanje slovenskega jezika.

\section{Ključne besede}

besednovrstno označevanje, klasifikacija, procesiranje naravnega jezika, jezikovne tehnologije

\section{UVOD}

Pri opazovanju samostojnih besed $\mathrm{v}$ besedilu naletimo na pojav večpomenskosti, katero lahko zmanjšamo s povezovanjem individualne besede $\mathrm{v}$ lokalni kontekst $\mathrm{s}$ sosednjimi besedami. Besednovrstno označevanje je postopek, katerega cilj je določitev besedne vrste besedi na podlagi konteksta, ki ga predstavljajo sosednje besede oz. značilke teh besed. Besednovrstni označevalnik je torej sistem, ki samodejno izvaja besednovrstno označevanje. Za praktično uporabo mora biti robusten, učinkovit, natančen in prenosljiv [8].

Poznamo dve vrsti besednovrstnih označevalnikov, in sicer označevalnike na osnovi pravil (angl. rule-based taggers) ter stohastične označevalnike (angl. stochastic taggers). Slednji dosegajo visoko stopnjo točnosti brez sintaktične analize vhodnega besedila in se odločajo predvsem na podlagi verjetnosti s pomočjo statističnih tabel, v katerih je znanje o besedah predstavljeno posredno, medtem ko označevalniki na osnovi pravil uporabljajo množico definiranih pravil, s pomočjo katerih določijo besedno vrsto posamezne besede. $\mathrm{S}$ temi pravili je znanje o besedah zapisano neposredno [10, $5,4]$.
V [16] je opisan algoritem FLORS (angl. Fast, LOcal, Robust, Simple). Gre za besednovrstni označevalnik, ki zgradi kontekst in znanje o besedi, odvisno od njenega lokalnega okolja, namesto da bi iskal optimalno zaporedje besednih vrst za celotne stavke. Kontekst besede je sestavljen iz binarnih in numeričnih značilk, ki so skupaj z delovanjem samega algoritma podrobneje predstavljene $\mathrm{v}$ drugem poglavju.

Uspešnost algoritma FLORS nad slovenskim jezikom smo skušali izboljšati z novimi značilkami. V drugem poglavju predstavimo sorodna dela, po katerih smo se zgledovali, v tretjem poglavju pa opišemo lastno idejo in komponente, ki smo jih potrebovali za izvedbo samega eksperimenta. V zadnjem poglavju rekonstruiramo rezultate originalnega algoritma nad izbranim slovenskim korpusom in jih nato primerjamo z rezultati nadgrajene različice algoritma.

\section{FLORS IN SORODNA DELA}

Pristopi k označevanju besed s strojnim učenjem uporabljajo različne metode učenja. V [7] pristopajo z nevronskimi mrežami in dosežejo visoko točnost, vendar pa sta tako izračun značilk kot tudi učenje mreže časovno zelo zahtevna procesa. $\mathrm{V}$ drugih delih so uporabili preprostejše značilke in nekatere druge metode strojnega učenja.

Uporaba strojnega učenja po metodi s podpornimi vektorji (angl. Support Vector Machine, $S V M$ ) za besednovrstno označevanje je bila objavljena v [20]. Z omejitvijo na lokalni kontekst so avtorji dosegli hitro učenje in izvajanje modela. Na zbirki besedil Wall Street Journal (WSJ) so dosegli točnost označevanja $97,16 \%$. Težave so se pojavile ob aplikaciji za drugo domeno. To problematiko so reševala kasnejša dela.

V [6] so avtorji predstavili nov način za povečanje robustnosti besednovrstnega označevanja. Metoda deluje na podlagi dveh ločenih modelov (splošnega in domensko specifičnega), naučenih na istih podatkih, a z različnimi značilkami. Za učenje splošnega modela so uporabili n-grame, ki so se v be- 
sedilu pojavili vsaj trikrat, za učenje domensko specifičnega modela pa n-grame, ki so se pojavili najmanj enkrat. Pri dekodiranju se uporabita oba modela tako, da se izbrani model spreminja dinamično glede na trenutno vhodno poved. Pri tem je izbira modela odvisna od podobnosti vhodne povedi podatkom, ki so jih uporabili za učenje algoritma. Takšen pristop dinamične izbire modela se nato uporabi v kombinaciji z algoritmom besednovrstnega označevanja, ki deluje $\mathrm{v}$ enem prehodu od leve proti desni. Algoritem je bil naučen na zbirki Wall Street Journal (WSJ), za testiranje delovanja algoritma pa so avtorji uporabili korpuse iz sedmih različnih domen. Ob testiranju so dosegli povprečno točnost besednovrstnega označevanja 70,54\% [6].

Algoritem FLORS [16] se loti domenske adaptacije na drugačen način. Uči se na označenih podatkih izvorne domene, hkrati pa uporabi nekaj statističnih podatkov neoznačenega besedila iz ciljne domene. Algoritem deluje hitro, saj za učenje in izvajanje uporablja le omejeno okolico posamezne besede (v nadaljevanju: kontekst) in preproste značilke; statistični podatki iz neoznačenega besedila pa zahtevajo zgolj preštevanje pojavitev. Avtorji definirajo štiri skupine značilk (slika 1), ki jih je možno ovrednotiti z uporabo zgolj trenutne besede in vnaprej pripravljene statistike.

Prva skupina značilk se nanaša na bigrame in njihove pojavitve v učnem korpusu. Bigram predstavimo tako, da trenutni besedi določimo za predhodnika eno od 500 najpogostejših besed v korpusu. Število pojavitev posameznega bigrama logaritmično obtežimo in tako tvorimo 500 značilk. Vse manj pogoste besede obravnavamo kot identične in na enak način tvorimo še eno dodatno značilko, s čimer se izognemo ničelnemu vektorju.

Podobno tvorimo drugo skupino značilk, le da tokrat trenutni besedi namesto predhodnika pripenjamo naslednika, kot vidimo na sliki $1(\mathrm{~b})$. Značilke na osnovi pogostih sosedov doprinesejo koristno informacijo o besednih vrstah $[17,18]$.

Tretja skupina značilk je množica binarnih značilk za ujemanje pripone s priponami besed v neoznačenem besedilu. Drugače, kot je to storjeno v sorodnih delih [19, 14], FLORS uporabi vse pripone vseh besed. Tako se izognemo potrebi po izbiranju podmnožice pripon.

Nazadnje dodajo še značilke za 16 posebej izbranih lastnosti besede, kot so vsebovanje števk, vezajev in velikih začetnic, pa tudi ujemanje s pogostimi končnicami angleškega jezika.

Predstavljen postopek določi približno 100.000 značilk na besedo. Največji delež značilk sestavljajo značilke tretje skupine. Na sliki 2 je prikazano, kako iz značilk besed sestavimo vektor značilk konteksta. Značilke konteksta uporabimo za nadzorovano učenje klasifikacijskega modela. Avtorji uporabijo okno dolžine petih besed, torej učimo s 500.000 vhodnimi diskretnimi atributi. Model klasificira besede v razrede glede na njihovo slovnično besedno vrsto. Podobno kot v [20] in [6] tudi pri FLORS učimo po metodi $S V M$ s pristopom One-Vs-All.

$\mathrm{Na}$ izvorni domeni so avtorji dosegli točnost 96,59 \%, pri adaptaciji na različne ciljne domene pa med $89,44 \%$ in 94,71 $\%$. a) bigrami s predhodnikom

b) bigrami z naslednikom

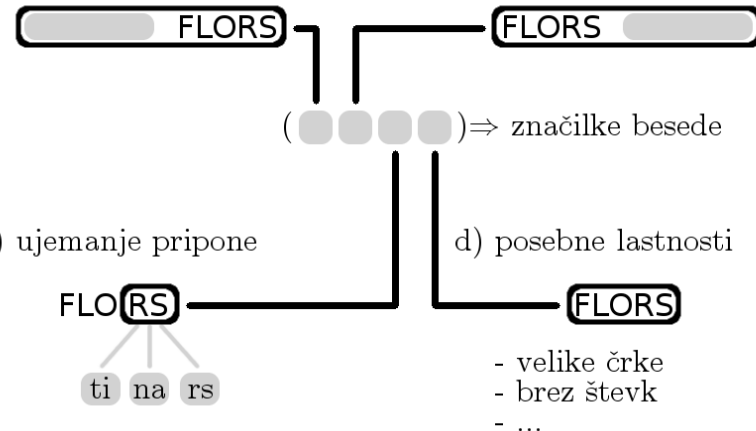

Slika 1: Vektor značilk posamezne besede po algoritmu FLORS na primeru besede "FLORS". a) prva in b) druga skupina značilk so frekvence bigramov, ki jih sestavimo $s$ trenutno besedo in pogostimi besedami učnega korpusa. Dodamo c) binarne značilke za ujemanje pripone in d) nekaj dodatnih značilk za posebne lastnosti besede.

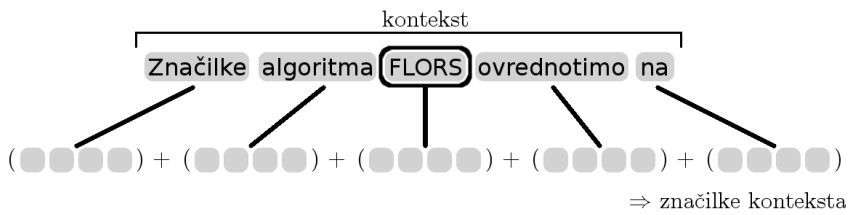

Slika 2: Vektor značilk konteksta po algoritmu FLORS dobimo tako, da združimo vektorje značilk besed v lokalnem oknu. Prikazan je primer zaporedja besed "Značilke algoritma FLORS ovrednotimo na". 
V našem delu prilagodimo algoritem FLORS za klasifikacijo besednih vrst $\mathrm{v}$ slovenskem jeziku, kar opišemo v naslednjem poglavju.

\section{ALGORITEM}

Nadgradnjo algoritma FLORS smo izvedli z dodatnimi značilkami, izbranimi za točnejše označevanje besednih vrst $\mathrm{v}$ slovenskem jeziku. Posebno pozornost smo namenili šumnikom in besednim priponam, ki so pogosto uporabljene v slovenskem jeziku, v angleščini pa niso prisotne.

$\mathrm{Na}$ podlagi analize besednih vrst in njihovih značilnosti $\mathrm{v}$ slovenščini smo izpeljali množico predpon in pripon, ki jih predstavimo v naslednjem podpoglavju.

Naša hipoteza je bila, da se bo z izpeljanimi značilkami točnost besednovrstnega označevanja nad slovenskimi besedili izboljšala.

\subsection{Značilke}

Obstoječim značilkam algoritma FLORS smo dodali binarne značilke, ki jih lahko razvrstimo v naslednje skupine:

- predponi $\boldsymbol{u}$ in $\boldsymbol{v}$. Predponi se lahko umestita na začetek različnih besednih vrst. Med glagoli lahko najdemo naslednje primere uporabe omenjenih predpon: u-krasti, u-pasti, v-plačati, v-pisati.

- Predpone sestavljenk. Predponi od- in $n a$ - se lahko uporabita na začetku sestavljenke (npr. od-dati, odzgoraj, na-pisati, na-govoriti).

- Pripone izpeljank. Pripone -lec, -ec, -arna se lahko uporabijo kot končine sestavljenk (npr. bra-lec, pisec, knjig-arna). Pri izpeljavi del dvodelne podstave zamenjamo s priponskim obrazilom.

- Končnice pridevnikov in pridevniških zaimkov. Končnica - $r a$ se pojavi pri pridevnikih (npr. dob-ra), končnica -ja pa se lahko pojavi pri pridevniških zaimkih (npr. mo-ja, tvo-ja).

- Sprememba pri soglasniških premenih. Za besede $\mathrm{s}$ končnico - $c i$ se črka $\mathrm{k} \mathrm{v}$ velelniku spremeni $\mathrm{v}$ črko c (npr. tekel - teci), kar imenujemo mehčanje ali palatizacija. Za besede $\mathrm{s}$ končnico $-z i$ se črka $\mathrm{g} \mathrm{v}$ velelniku spremeni v črko z (npr. vrgel - vrzi).

- Končnice samostalniških besed. Pri besedah ženskega spola ima samostalniška beseda končnico - $a$, pri srednjem spolu pa -o. Naslednji primeri so posamostaljene pridevniške besede: dobra, tista, dobro, tisto.

- Končnice vrstnih pridevnikov. Z končnicama ski in -ški lahko razpoznamo vrstne pridevnike (npr. fotograf-ski, potaplja-ški).

- Obrazilo v kombinaciji s podstavo. Pri besedotvorju se lahko končnici -ica in -ost pojavita kot obrazilo, skupaj s podstavo pa tvorita novo besedo. Uporabili smo desna obrazila (npr. miz-ica, mlad-ost).
- Pripone besedotvorne vrste sklop. Končnice -to, -tem, -deset se lahko pojavijo kot pripone pri besedotvorni vrsti sklop, ki nastane s sklaplanjem, kjer posamezne dele večdelne podstave združimo v novo besedo (npr. na-to, po-tem, dva-in-tri-deset).

- Naglasna, naslonska ali navezna sklonska oblika. Končnice -ga, -ne, -me se pojavijo kot pripone naglasnih, naslonskih ali naveznih sklonskih oblik osebnega zaimka (npr. nje-ga, me-ne, na-me).

- Pripone kazalnih zaimkov. Priponi $-t a$ in $-t i$ se pojavita pri kazalnih zaimkih (npr. ta, tis-ti).

- Pripone vprašalnih zaimkov. Končnice $-a j$, -em, -im, -en in -od se pojavijo v vprašalnih zaimkih (npr. k-aj, kater-em, kater-im, kakš-en, k-od).

- Šumniki Posebnost slovenskega jezika so šumniki $\check{c}, \check{s}$ in $\check{z}$.

Binarne značilke predstavljajo prisotnost predpon, pripon in šumnikov. Opisane značilke zajemajo morfološke značilnosti slovenskega jezika in jih uvrščamo med oblikovne (angl. shape) značilke algoritma FLORS. Obdržali smo ortografski del značilk (ali beseda vsebuje števko, poševnico, veliko začetnico). Izpostaviti moramo dejstvo, da se zaradi kompleksnosti gramatike slovenskega jezika nekatere značilke pojavijo tudi pri vrstah besed, za katere niso bile $\mathrm{v}$ osnovi zasnovane.

\subsection{Analiza poglavitnih komponent}

Osrednji namen analize poglavitnih komponent (angl. Principal Component Analysis, PCA) je zmanjšanje števila dimenzij množice podatkov, ki jih sestavlja veliko število koreliranih spremenljivk, ne da bi pri tem okrnili izraznost podatkov. Učinek je dosežen s pomočjo transformacije spremenljivk v novo množico, ki jo imenujemo množica poglavitnih komponent (angl. principal components). Poglavitne komponente med seboj niso odvisne, ohranjajo pa kar največjo stopnjo raznolikosti podatkov, ki je prisotna v originalnih spremenljivkah, s čimer zagotovijo, da je z njihovo pomočjo podatke med seboj možno ustrezno razlikovati. Tako za ceno nekaj točnosti dobimo enostavnejšo predstavitev, s čimer poenostavimo analizo in obdelavo podatkov [12].

Naj bo $x$ vektor $p$ naključnih spremenljivk. V procesu določanja poglavitnih komponent nas zanimajo raznolikosti in korelacije med spremenljivkami. Če vrednost $p$ ni majhna, ni smiselno pregledovati vseh možnih povezav med spremenljivkami $x$, zato se raje osredotočimo na nekaj $(\ll p)$ izpeljanih spremenljivk, ki vsebujejo kar največ informacij v zvezi $\mathrm{z}$ raznolikostjo, korelacijo in kovarianco med originalnimi spremenljivkami. PCA izpelje spremenljivke, odvisno od tipa podatkov, na podlagi kovariančne ali korelacijske matrike, ki opisujeta, na kakšen način so izvorne spremenljivke med seboj povezane. Gre za simetrični matriki, velikosti $p \times p$. Izpeljane spremenljivke so linearne kombinacije izvornih spremenljivk in so med seboj nekorelirane, torej gre za ortogonalne vektorje, ki predstavljajo smeri, v katerih se kaže največja raznolikost podatkov. Te kombinacije oz. poglavitne komponente so izpeljane in urejene na način, da se 


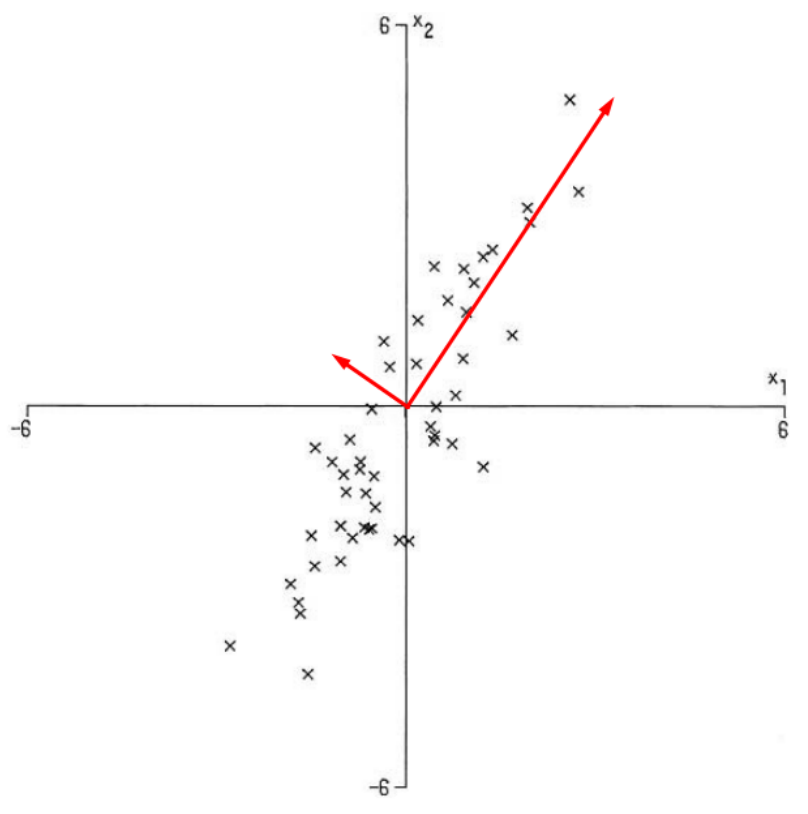

Slika 3: Graf originalnih podatkov za spremenljivki $x_{1}$ in $x_{2} \mathbf{z}$ označenima poglavitnima komponentama. Vir: [12]

v začetnih komponentah nahaja čim več, v kasnejših komponentah pa vedno manj informacij. Med $p$ izpeljanimi spremenljivkami je cilj izbrati nekaj prvih $(\ll p)$, ki vsebujejo največ informacij in s tem ohraniti izraznost podatkov kljub zmanjšanju števila dimenzij [12].

Za enostaven, sicer nerealen, prikaz delovanja PCA privzamemo, da je $p=2$. Na ta način lahko prikažemo podatke $\mathrm{v}$ dveh dimenzijah. Slika 3 prikazuje primer grafa za dve spremenljivki $x_{1}$ in $x_{2}$, ki sta v korelaciji. Spremenljivost je prisotna tako v smeri $x_{1}$ kot tudi v smeri $x_{2}$, če pa vse skupaj pretvorimo $\mathrm{v}$ domeno poglavitnih komponent, dobimo spremenljivki $z_{1}$ in $z_{2}$ ter s tem graf, ki ga prikazuje slika 4 [12]. Iz slike 4 je vidno, da so spremembe v smeri $z_{1}$ velike, medtem ko je variacija $\mathrm{v}$ smeri $z_{2}$ majhna. Če so spremenljivke med seboj močno korelirane, bo prvih nekaj poglavitnih komponent odraz večine variacij originalnih spremenljivk, medtem ko bodo naslednje poglavitne komponente predstavljale smeri, kjer ni veliko raznolikosti. Z drugimi besedami, prve poglavitne komponente vsebujejo večino informacij [12].

Primeri apliciranja PCA na razna področja so:

- identifikacija pomembnih virov raznolikosti pri anatomskih meritvah različnih življenjskih vrst;

- analiza demografskih informacij, pridobljenih s pomočjo anketiranja starejšega prebivalstva Združenega kraljestva;

- pregled prostorskih in časovnih sprememb v atmosferskih znanostih;

- določanje pomembnih povezav med lastnostmi kemijskih spojin;

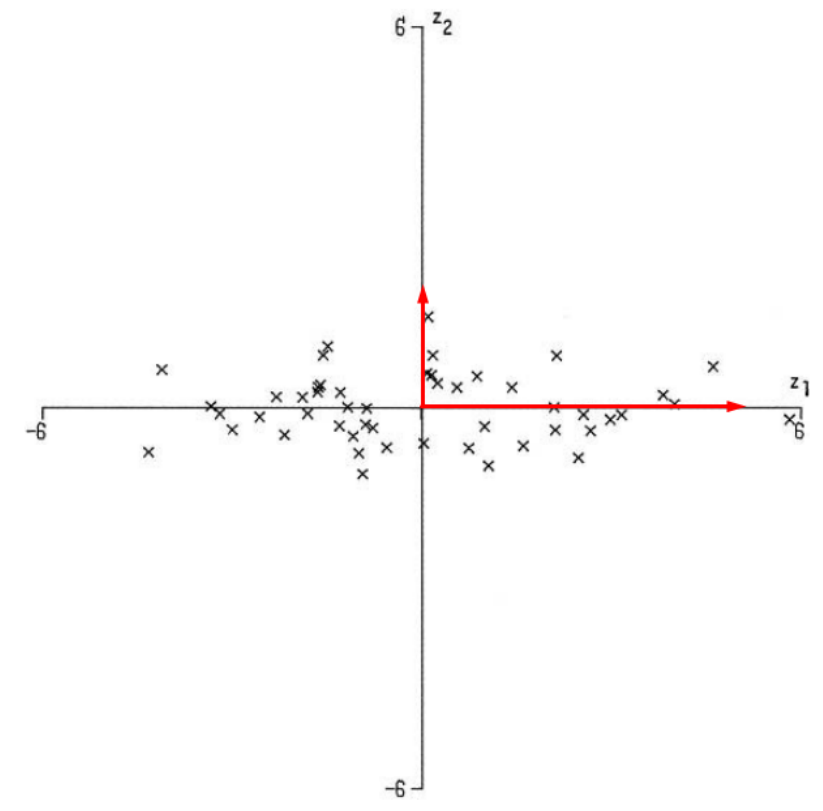

Slika 4: Graf glede na spremenljivki $z_{1}$ in $z_{2}$ z označenima poglavitnima komponentama $\mathrm{v}$ prostoru poglavitnih komponent. Vir: [12]

- analiza borznih cen [12].

\subsection{Uporabljeni klasifikatorji}

Za klasificiranje besednih vrst smo uporabili tri različne klasifikatorje, in sicer One-vs-All $S V M$ z linearnim jedrom, Naivni Bayes ter Random Forest. Posameznim parametrom pri vsakem izmed uporabljenih klasifikatorjev se nismo posebej posvečali, pri testiranju pa smo uporabili petkratno navzkrižno preverjanje. V tem podpoglavju bomo na kratko opisali vsakega izmed uporabljenih klasifikatorjev.

\subsubsection{One-vs-All SVM}

SVM je metoda strojnega učenja z uporabo nadzorovanega učenja, ki jo lahko uporabimo tako za klasifikacijo kot regresijo. Pri tej metodi vsak primerek iz učne množice predstavimo kot točko v n-dimenzionalnem prostoru, pri čemer $\mathrm{n}$ predstavlja število značilk primerka. Algoritem nato najde optimalno hiperravnino, ki najbolje razdeli dva razreda.

Naloga metode SVM je najti optimalno hiperravnino izmed vseh, ki ločujejo primerke na dva razreda, pri čemer primerki enega razreda ležijo pod, primerki drugega razreda pa nad hiperravnino. Primerki, ki ležijo nad hiperravnino, so pozitivni, primerki pod hiperravnino pa negativni. Najprej poiščemo v vsakem razredu primerek, ki leži najbližje delilni hiperravnini. Izbranim primerkom pravimo podporni vektorji (angl. support vectors). Skozi njiju potegnemo vzporednici, ki jima pravimo pozitivna in negativna ravnina. Razdaljo med tema dvema ravninama imenujemo rob (angl. margin). Optimalna delilna ravnina je tista, pri kateri je velikost roba maksimalna. Razred, kateremu pripada posamezen primerek, določimo glede na to, na kateri strani delilne ravnine se nahaja. Na sliki 5 lahko vidimo delilno, pozitivno ter negativno hiperravnino [13]. 


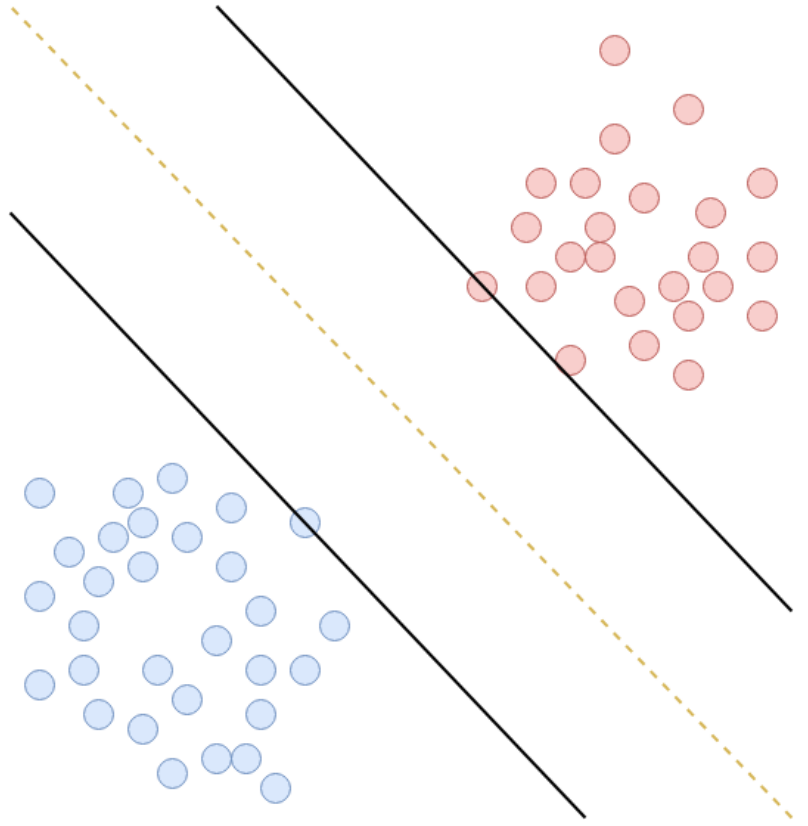

Slika 5: Prikaz hiperravnin pri metodi SVM.

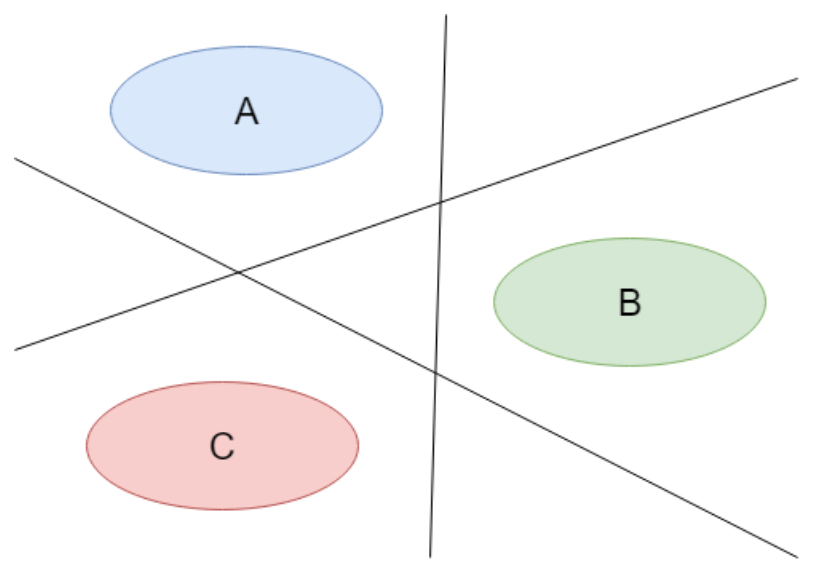

Slika 6: Prikaz večrazredne klasifikacije SVM z metodo One-vs-All.

Če želimo SVM uporabiti za klasifikacijo v več razredov, moramo uporabiti eno izmed metod za večrazredno klasifikacijo. V naši implementaciji algoritma FLORS smo uporabili metodo One-vs-All. Metoda za vsak razred ustvari binarni klasifikator SVM. Vsak $i$-ti klasifikator razdeli primerke na tiste, ki spadajo $\mathrm{v} i$-ti razred in tiste, ki ne. Primer večrazredne klasifikacije SVM z metodo One-vs-All je prikazan na sliki $6[1]$.

\subsubsection{Naivni Bayes}

Klasifikator Naivni Bayes je del družine enostavnih verjetnostnih klasifikatorjev, ki temeljijo na uporabi Bayesovega pravila. Njegova uporaba je popularna predvsem na področju klasifikacije besedila ter zaznavanja neželjene pošte.

$$
P(A \mid B)=\frac{P(B \mid A) P(A)}{P(B)}
$$

S pomočjo Bayesovega pravila, zapisanega v enačbi (1), lahko poiščemo verjetnost, da se zgodi dogodek A v primeru, da se je zgodil dogodek B.

Pri klasifikaciji s pomočjo Naivnega Bayesa se odločamo o tem, v kateri razred spada določen primerek glede na vrednosti njegovih značilk. Glavna predpostavka, na kateri temelji ta algoritem je, da so vse značilke posameznega primerka pogojno neodvisne druga od druge pri danem razredu. Prav tako predpostavimo, da ima vsaka značilka enak vpliv na odločitev klasifikatorja. Če dogodek A iz enačbe (1) sedaj zamenjamo s klasifikacijskim razredom $y$, ter dogodek B z vektorjem značilk $X$, potem lahko Bayesovo pravilo zapišemo $\mathrm{z}$ enačbo (2).

$$
P(y \mid X)=\frac{P(X \mid y) P(y)}{P(X)}
$$

Ker je dogodek $X$ presek več dogodkov oz. značilk, lahko zapišemo enačbo (3).

$$
P\left(y \mid x_{1}, x_{2}, \ldots, x_{n}\right)=\frac{P\left(x_{1} \mid y\right) P\left(x_{2} \mid y\right) \ldots P\left(x_{n} \mid y\right) P(y)}{P\left(x_{1}\right) P\left(x_{2}\right) \ldots P\left(x_{3}\right)}
$$

Vrednost izraza $\mathrm{v}$ imenovalcu je enaka za vse primerke $\mathrm{v}$ množici, zato se lahko imenovalca znebimo in uvedemo odvisnost. Tako dobimo enačbo (4).

$$
P\left(y \mid x_{1}, x_{2}, \ldots, x_{n}\right) \propto P(y) \prod_{i=1}^{n} P\left(x_{i} \mid y\right)
$$

Primerek uvrstimo v razred $y$, dobljen $z$ enačbo (5), ki vrne razred z najvišjo verjetnostjo $[11,3]$.

$$
y=\operatorname{argmax}_{y} P(y) \prod_{i=1}^{n} P\left(x_{i} \mid y\right)
$$

\subsubsection{Random Forest}

Klasifikator Random Forest je metoda nadzorovanega strojnega učenja. Spada v t.i. ansambelske metode, katerih značilnost je, da združujejo več klasifikatorjev enakih ali različnih vrst v en skupen klasifikator. Ideja ansambelskih metod je, da več slabših klasifikatorjev skupaj deluje bolje kot en dober klasifikator. Klasifikator Random Forest je sestavljen iz več različnih odločitvenih dreves, ki jih naučimo na naključni podmnožici primerkov iz učne množice z naključno izbrano podmnožico značilk. Končno klasifikacijo dobimo tako, da združimo odločitve posameznih odločitvenih dreves. Generalna shema algoritma je prikazana na sliki $7[9$, $15]$. 


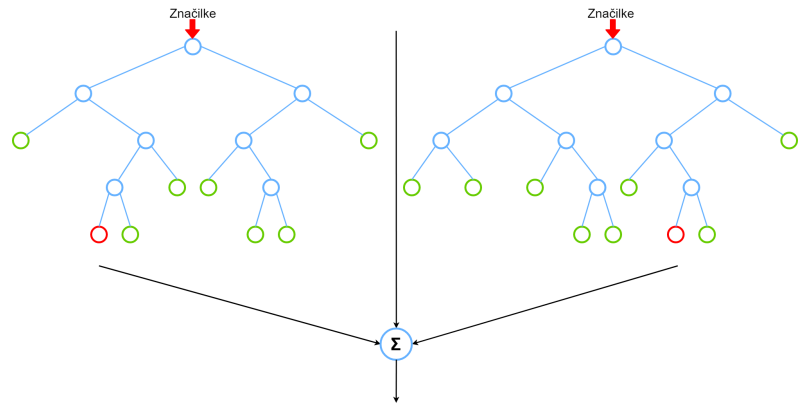

Slika 7: Shema algoritma Random Forest.

\section{REZULTATI}

Algoritem smo preizkusili nad korpusom jos100k ${ }^{1}$. Z izvornim algoritmom FLORS smo nad slovenskim besedilom dosegli uspešnost 83,05 \% po metriki F1. Po odstranitvi morfoloških značilk, vezanih na angleški jezik, ter izvajanju analize poglavitnih komponent smo dosegli 85,16\%. Algoritem PCA je vedno izboljšal rezultate, saj z zmanjšanjem dimenzije iskalnega prostora dosežemo boljšo generalizacijo in $\mathrm{s}$ tem višjo točnost klasifikacije prej nevidenih podatkov. Najboljše rezultate smo uspeli doseči z algoritmom SVM, katerega rezultati pri različnem naboru značilk so vidni na sliki 8. Z dodajanjem značilk, vezanih na pogoste predpone in končnice $\mathrm{v}$ slovenskem jeziku, nam uspešnosti klasifikacije ni uspelo izboljšati.

Klasifikacijo besednih vrst smo izvedli s tremi različnimi klasifikacijskimi algoritmi. Prej omenjeno točnost smo dosegli z metodo podpornih vektorjev, ki ga uporablja tudi izvorni algoritem FLORS. Modela Naivni Bayes in Random Forest sta bila manj uspešna kot SVM. Na slikah 9 in 10 vidimo klasifikacijske rezultate modelov nad testno množico podatkov.

Rezultate najuspešnejšega modela nad individualnimi besednimi vrstami si ogledamo z matriko napak na sliki 11 . Napake so pogoste pri klasifikaciji razreda "medmet"in "neuvrščeno". Napačno uvrstitev medmetov obrazložimo z dejstvom, da medmeti ne upoštevajo slovničnih pravil in se lahko pojavijo v mnogih oblikah, na primer z različnim številom zaporednih pojavitev iste črke. Poleg tega je število medmetov v učnem korpusu majhno. Razred "neuvrščeno"je slabo definiran, saj vsaka beseda pripada določeni besedni vrsti. Razred "neuvrščeno"predstavlja zgolj manjkajoče podatke v učni množici. Model bo takšno besedo uvrstil v drug razred, ki je z veliko verjetnostjo celo pravilen.

\section{ZAKLJUČEK}

V sklopu dela smo implementirali algoritem besedovrstnega označevanja FLORS [16] in na različne načine skušali izboljšati njegovo delovanje na slovenskem jeziku. FLORS definira nabor značilk, ki se uporabijo za učenje modela linearni SVM za označevanje angleškega jezika. Odstranili smo značilke, vezane izključno na angleščino, s čimer smo dvignili uspešnost označevanja. Poskusili smo dodati nove značilke na osnovi morfoloških značilnosti slovenščine, vendar smo opazili, da je to znižalo točnost rezultatov. Preizkusili smo

\footnotetext{
${ }^{1}$ Dostopno na http://nl.ijs.si/jos
}

učna modela Naivni Bayes in Random Forest, vendar sta se izkazala kot manj uspešna v primerjavi s SVM. Nazadnje smo uspeli uspešnost še dodatno povečati z uporabo algoritma za analizo poglavitnih komponent (PCA). Najvišja uspešnost, ki smo jo s tem dosegli, je $85,16 \%$ po metriki F1.

Na podlagi rezultatov sklepamo, da uspešnost algoritma FLORS na slovenščini ni primerljiva $\mathrm{z}$ uspešnostjo drugih metod besednovrstnega označevanja [2]. Algoritem FLORS je preprost in hiter, a s preprostimi značilkami ne uspe zajeti kompleksnosti slovenskega jezika. Predpona in končnica ne nudita koristnih informacij o besedni vrsti, ker ima beseda preveč oblik, v katerih se lahko pojavi. Dodatne značilke, ki ne pripomorejo $\mathrm{k}$ razlikovanju med besednimi vrstami, povzročijo, da se dimenzija iskalnega prostora poveča in uspešnost klasifikacijskega modela zmanjša.

Točnost lahko povečamo z izključitvijo tistih obstoječih značilk, ki so nekoristne za označevanje besednih vrst slovenskega jezika. Odstranitev morfoloških značilk angleškega jezika je prvi korak k poenostavitvi algoritma in izboljšanju klasifikacijskih rezultatov. Transformacija PCA dodatno zmanjša dimenzijo prostora značilk, kar pri vsakem naboru značilk poveča točnost klasifikatorja linearni SVM.

V nadaljnjem delu se bomo osredotočili na slovnične operacije, s katerimi bi lažje obvladovali kompleksnost slovenskega jezika in izpeljali značilke, ki bi povečale točnost besednovrstnega označevanja. Smiselno bi bilo uporabiti tudi metode s področja lematizacije, saj bi z osnovnimi oblikami besed lažje določili njihove besedne vrste.

\section{VIRI}

[1] B. Aisen. A comparison of multiclass svm methods, 2006.

[2] P. Belej, M. Robnikv Sikonja, and S. Krek. Character-level part-of-speech tagger of slovene language, 2019. Slovenian language resource repository CLARIN.SI.

[3] M. Bozhinova. NAIVNI BAYESOV KLASIFIKATOR. $\mathrm{PhD}$ thesis, Univerza v Mariboru, Fakulteta za elektrotehniko, računalništvo in informatiko, 2015.

[4] E. Brill. A simple rule-based part of speech tagger. In Proceedings of the Third Conference on Applied Natural Language Processing, ANLC '92, pages 152-155, Stroudsburg, PA, USA, 1992. Association for Computational Linguistics.

[5] E. Brill. Some advances in transformation-based part of speech tagging. CoRR, abs/cmp-lg/9406010, 1994.

[6] J. Choi and M. Palmer. Fast and robust part-of-speech tagging using dynamic model selection. volume 2, pages 363-367, 072012.

[7] R. Collobert, J. Weston, L. Bottou, M. Karlen, K. Kavukcuoglu, and P. Kuksa. Natural language processing (almost) from scratch. Computing Research Repository - CORR, 12, 032011.

[8] D. Cutting, J. Kupiec, J. Pedersen, and P. Sibun. A practical part-of-speech tagger. In Proceedings of the Third Conference on Applied Natural Language Processing, ANLC '92, pages 133-140, Stroudsburg, PA, USA, 1992. Association for Computational 


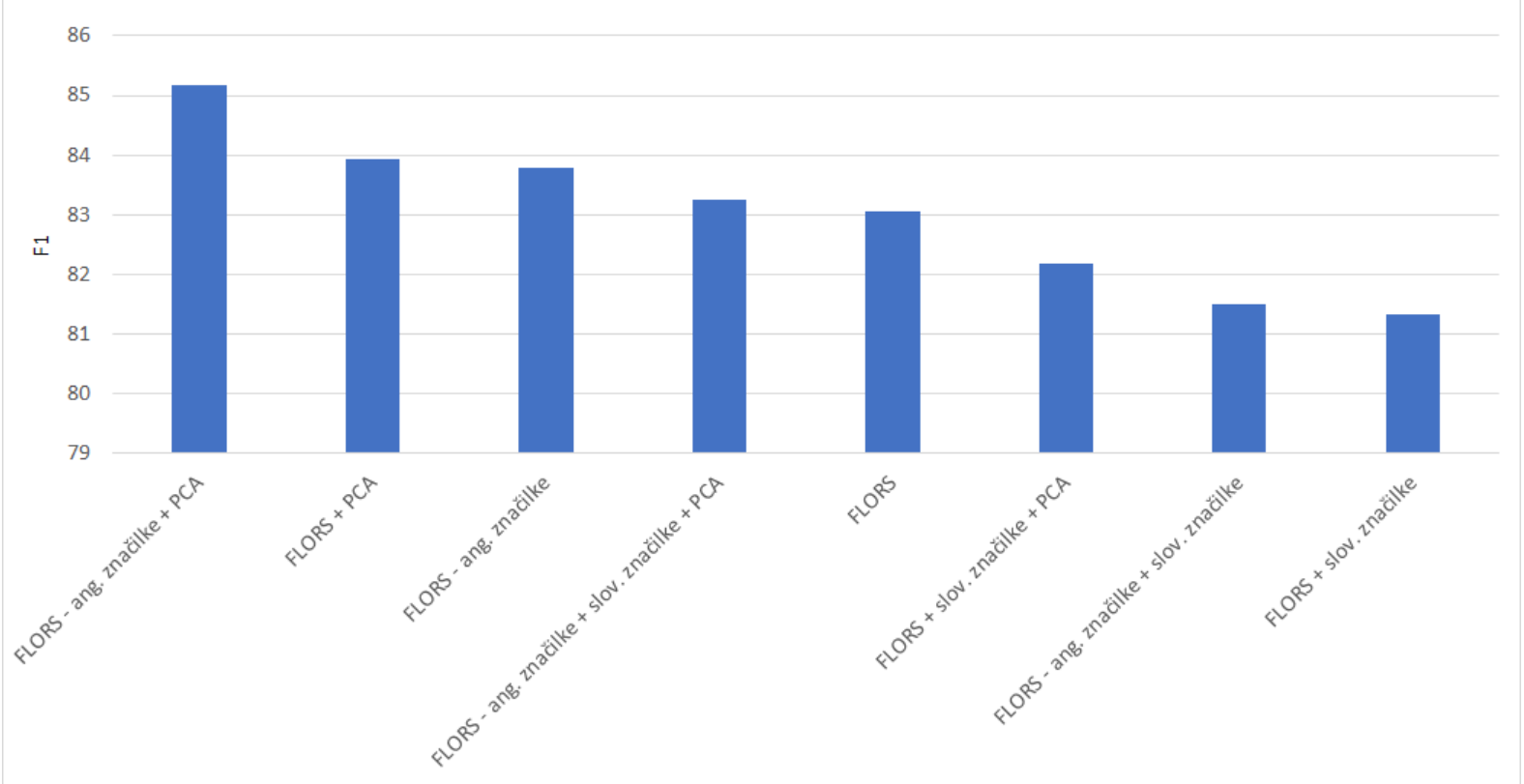

Slika 8: Urejeni rezultati metrike F1 pri klasifikacijskem modelu SVM za dodane slovenske morfološke značilke, odstranjene angleške morfološke značilke in apliciranje transformacije PCA.

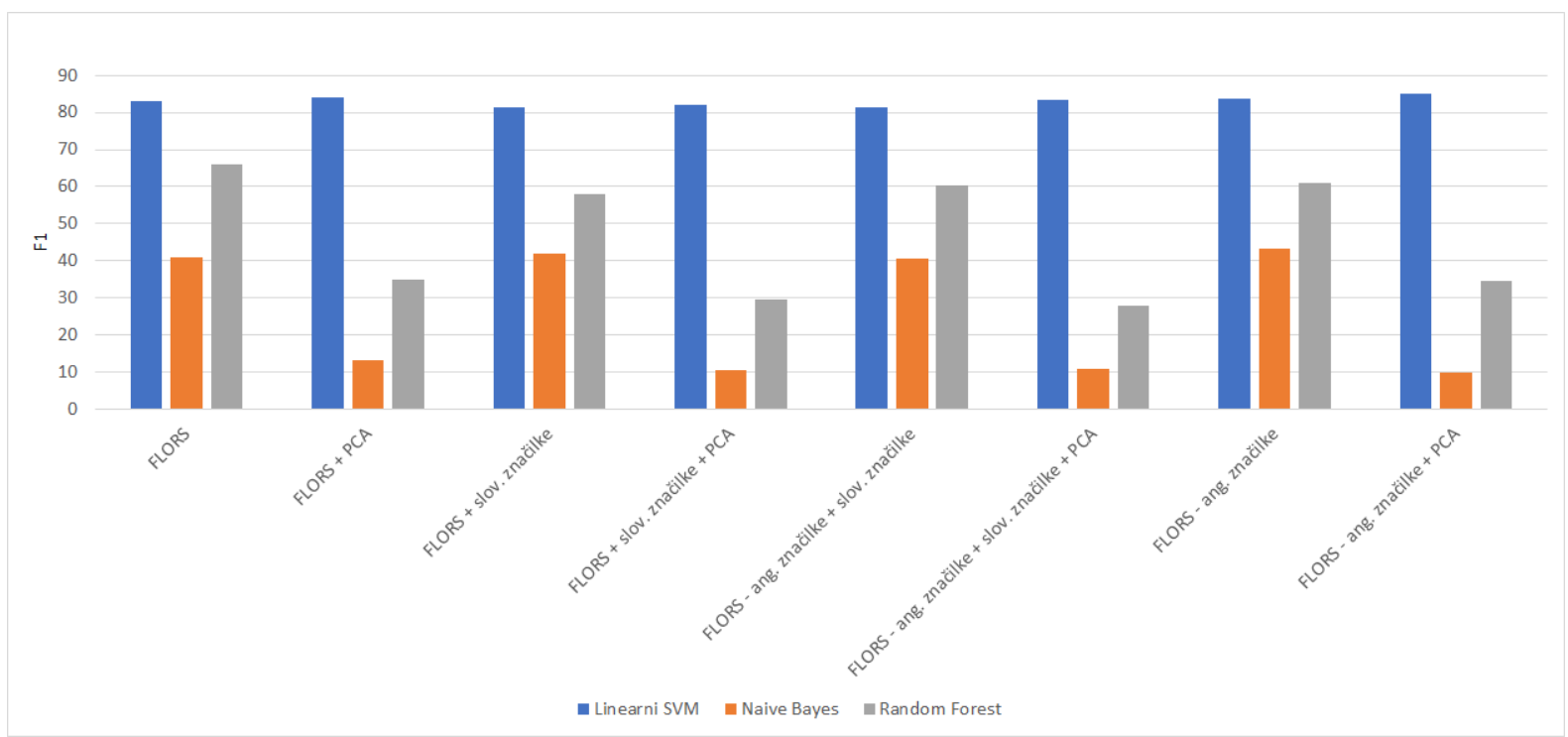

Slika 9: Rezultati metrike F1 za modele SVM, Naivni Bayes in Random Forest.

Slika 10: Vrednosti metrike F1 klasifikacijskih modelov SVM, učenih z različnimi nabori značilk: dodane slovenske morfološke značilke, odstranjene angleške morfološke značilke in apliciranje transformacije PCA.

\begin{tabular}{|l|l|l|l|}
\hline & Linearni SVM & Naivni Bayes & Random Forest \\
\hline FLORS & $83.05 \%$ & $40.81 \%$ & $65.83 \%$ \\
\hline FLORS + PCA & $83.94 \%$ & $13.03 \%$ & $34.77 \%$ \\
\hline FLORS + slov. značilke & $81.32 \%$ & $42.03 \%$ & $57.96 \%$ \\
\hline FLORS + slov. značilke + PCA & $82.19 \%$ & $10.49 \%$ & $29.64 \%$ \\
\hline FLORS - ang. značilke + slov. značilke & $81.51 \%$ & $40.63 \%$ & $60.22 \%$ \\
\hline FLORS - ang. značilke + slov. značilke + PCA & $83.24 \%$ & $10.83 \%$ & $27.81 \%$ \\
\hline FLORS - ang. značilke & $83.79 \%$ & $43.16 \%$ & $61.05 \%$ \\
\hline FLORS - ang. značilke + PCA & $85.16 \%$ & $9.65 \%$ & $34.59 \%$ \\
\hline
\end{tabular}




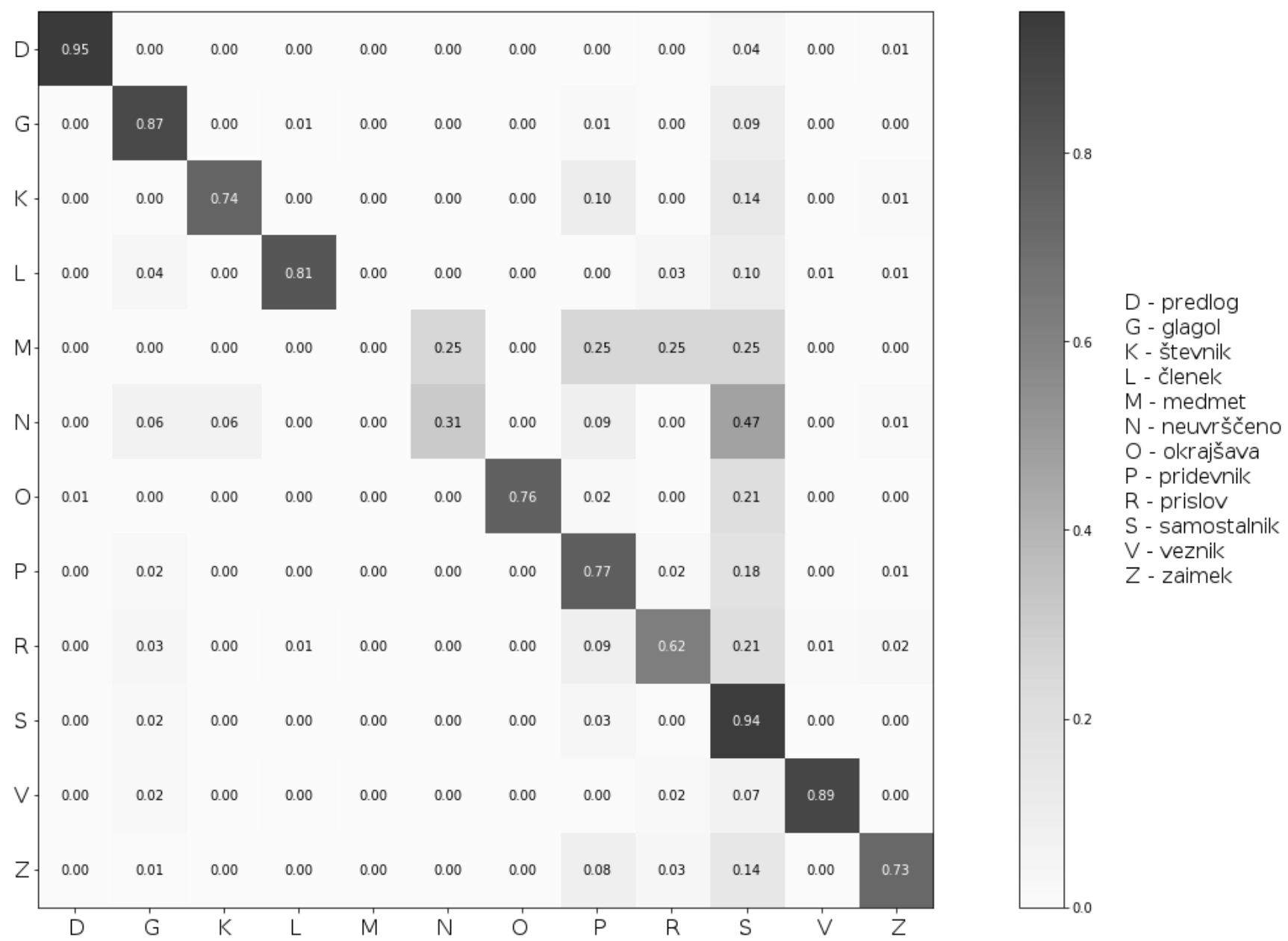

Slika 11: Matrika zmot algoritma FLORS po metriki F1 z modelom SVM z odstranjenimi angleškimi morfološkimi značilkami in po uporabi PCA. Prikazana je točnost klasifikacije posamezne besedne vrste. Stolpec predstavlja razred, v katerega smo besedo uvrstili. Vrstica predstavlja dejanski razred besede. 
Linguistics.

[9] N. Donges. The random forest algorith, 2018.

[10] P. F. Brown, V. Dellapietra, P. V. de Souza, J. Lai, and R. Mercer. Class-based n-gram models of natural language. Computational Linguistics, 18:467-479, 01 1992.

[11] R. Gandhi. Naive bayes classifier, 2018.

[12] I. Jolliffe. Principal Component Analysis, pages 1094-1096. Springer Berlin Heidelberg, Berlin, Heidelberg, 2011.

[13] D. Kumar. Demystifying support vector machines, 2019.

[14] J. Miller, M. Torii, and K. Vijay-Shanker. Building domain-specific taggers without annotated (domain) data. pages 1103-1111, 012007.

[15] S. Patel. Chapter 5: Random forest classifier, 2017.

[16] T. Schnabel and H. Schütze. Flors: Fast and simple domain adaptation for part-of-speech tagging. Transactions of the Association for Computational Linguistics, 2:15-26, 122014.

[17] H. Schütze. Part-of-speech induction from scratch. pages 251-258, 011993.

[18] H. Schütze. Distributional part-of-speech tagging. page 141, 031995.

[19] K. Toutanova, D. Klein, C. Manning, and Y. Singer. Feature-rich part-of-speech tagging with a cyclic dependency network. Proceedings of the 2003 Conference of the North American Chapter of the Association for Computational Linguistics on Human Language Technology-NAACL '03, 1, 032004.

[20] J. Us Gim Enez and L. S M Arquez. Svmtool: A general pos tagger generator based on support vector machines. 072004. 